\title{
Cohesive Devices in Written Discourse: A Discourse Analysis of a Student's Essay Writing
}

\author{
Afnan Bahaziq ${ }^{1}$ \\ ${ }^{1}$ English Language Institute, King Abdul Aziz University, Jeddah, Saudi Arabia \\ Correspondence: Afnan Bahaziq, English Language Institute, King Abdul Aziz University, Jeddah, P.O. Box \\ 42890, Saudi Arabia. E-mail: abahaziq@kau.edu.sa
}

Received: January 13, 2016 Accepted: April 29, 2016 Online Published: May 16, 2016

doi: 10.5539/elt.v9n7p112 URL: http://dx.doi.org/10.5539/elt.v9n7p112

\begin{abstract}
Discourse is essential in communicating thoughts and ideas. People around the world communicate their ideas through stretches of language. In order to understand any discourse, it must achieve cohesion. The purpose of this paper is to define and describe the cohesive devices based on the work of Halliday and Hasan (1976). It also aims to emphasize the necessity of using these devices by analyzing a Michigan English Language Assessment Battery (MELAB) sample examination of a student's essay writing. The student's writing shows clear evidence of cohesion and demonstrates the use of grammatical and lexical devices. It is noticed that the most grammatical devices used are reference and conjunction. On the contrary, there is little evidence of using lexical devices. Although the essay is somewhat cohesive, some areas still need improvement.
\end{abstract}

Keywords: cohesive devices, grammatical and lexical devices, cohesion, student's writing

\section{Introduction}

English is considered the first language for the majority of the population in several countries and the second language for others. Hence, English is becoming the language of communication globally. Communication allows language users to interact with each other and in turn understand what others are trying to convey. In other words, language could be understood differently depending on the situation and context in which the discourse occurs. Discourse, then, is any spoken or written language which includes verbal and nonverbal elements that are meaningful.

An English native speaker can easily identify whether a set of sentences are unrelated or form a unified whole. The unity between these sentences is achieved through the use of cohesive devices. This paper aims to define and describe these cohesive devices based on Halliday and Hasan's (1976) work. It also aims to emphasize the necessity of using cohesive devices in written discourse by analyzing a Michigan English Language Assessment Battery (MELAB) sample examination of a student's essay writing.

\section{The Concept of Cohesion}

\subsection{Text and Texture}

In linguistics, any spoken or written discourse that forms a unified whole is referred to as a text. A text is not a grammatical unit, but rather a semantic unit of language, i.e. a unit of meaning, not of form. Texture is what provides the text with unity and distinguishes it from a non-text. Therefore, it is the cohesive relation that exists between units of a text.

\subsection{Cohesion}

Cohesion is the semantic relation between one element and another in a text (Halliday \& Hasan, 1976). A text is cohesive when the elements are tied together and considered meaningful to the reader. Cohesion occurs when the interpretation of one item depends on the other, i.e. one item presupposes the other (Halliday \& Hasan, 1976). For instance in the following text:

Amy went to the party. She sat with Sara.

The interpretation of the item she depends on the lexical item Amy. Therefore, the text is considered cohesive because we cannot understand the meaning of she unless Amy exists in the text. 
Cohesion is not only concerned with grammar, but also with vocabulary. Hence, it is divided into grammatical and lexical cohesion.

\subsection{Grammatical Cohesion}

Halliday and Hasan classify the categories of grammatical cohesion into four types: reference, substitution, ellipsis, and conjunction.

\subsubsection{Reference}

Reference can be identified as the situation in which one element cannot be semantically interpreted unless it is referred to another element in the text. Pronouns, articles, demonstratives, and comparatives are used as referring devices to refer to items in linguistic or situational texts. Reference may either be exophoric or endophoric (M. Bloor \& T. Bloor, 2013).

Exophoric reference requires the reader to infer the interpreted referent by looking beyond the text in the immediate environment shared by the reader and writer. For example in the sentence:

\section{That is a wonderful idea!}

To retrieve the meaning of that, the reader must look outside the situation.

On the other hand, endophoric reference lies within the text itself. It is classified into two classes: anaphoric and cataphoric. According to Paltridge (2012), "Anaphoric reference is where a word or phrase refers back to another word or phrase used earlier in the text" (p. 115). In the previous example:

Amy went to the party. She sat with Sara.

She refers back to Amy; therefore, she is an anaphoric reference. Cataphoric reference looks forward to another word or phrase mentioned later in the text. For instance in the following sentence, he is a cataphoric reference that looks forward to Mike.

As soon as he arrived, Mike visited his parents.

\subsubsection{Substitution}

Substitution occurs when an item is replaced by another item in the text to avoid repetition. The difference between substitution and reference is that substitution lies in the relation between words, whereas reference between meanings. There are three types of substitution: nominal, verbal, and clausal.

Nominal substitution is substituting a noun or a nominal group with another noun. Elements of this type are one, ones, and same. In the following example, one substitutes car.

\section{This car is old. I will buy a new one.}

Verbal substitution involves substituting a verb or a verbal group with another verb. The verb element used to replace items in this type is $d o$. For example:

\section{I challenge you to win the game before I do!}

Here, do is the substitution for win the game.

Clausal substitution is substituting clauses by so or not. This is illustrated by the following:

A: Do you think the teacher is going to be absent tomorrow?

B: No. I don't think so.

In this example, so substitutes the clause going to be absent.

\subsubsection{Ellipsis}

Ellipsis is the process of omitting an unnecessary item, which has been mentioned earlier in a text, and replacing it with nothing. It is similar to substitution because "Ellipsis is simply substitution by zero" (Halliday \& Hasan, 1976). Normally, it is considered as an anaphoric relation because the omission takes place within a text. When ellipsis occurs, the item that is omitted from the structure of the text, can still be understood. Alike substitution, ellipsis has three types: nominal, verbal, and clausal.

In nominal ellipsis, the noun is omitted. This is exemplified by:

My brothers like sports. In fact, both [0] love football. [0: My brothers]

In the second sentence, the nominal my brothers is omitted. 
Verbal ellipsis involves the omission of the verb. In the following example, the verb been studying is left out in B.
A: Have you been studying?
B: Yes, I have[0]. [0: been studying]

Clausal ellipsis occurs when the clause is omitted. In the example mentioned below, the clause writing on the board is excluded in B.

A: Who is writing on the board?

B: Alice is [0]. [0: writing on the board]

2.3.4 Conjunction

Conjunction words are linking devices between sentences or clauses in a text. Unlike the other grammatical devices, conjunctions express the 'logical-semantic' relation between sentences rather than between words and structures (Halliday \& Hasan, 1976). In other words, they structure the text in a certain logical order that is meaningful to the reader or listener. Conjunctions are divided into four types, namely additive, adversative, causal, and temporal.

Additive conjunctions connect units that share semantic similarity. Examples of additive conjunctions are, and, likewise, furthermore, in addition, etc.

Adversative conjunctions are used to express contrasting results or opinions. This type of conjunction is expressed by words such as, but, however, in contrast, whereas, etc.

Causal conjunctions introduce results, reasons, or purposes. They are characterized by the use of items such as, so, thus, therefore, because, etc.

Temporal conjunctions express the time order of events such as, finally, then, soon, at the same time, etc.

\subsection{Lexical Cohesion}

Lexical cohesion involves the choice of vocabulary. It is concerned with the relationship that exists between lexical items in a text such as words and phrases. Lexical cohesion includes two types, reiteration and collocation.

\subsubsection{Reiteration}

Halliday and Hasan (1976) define reiteration as two items that share the same referent and could either be repeated or have similar meanings in a text. The forms of reiteration are repetition, synonymy, antonymy, and superordination (hyponymy and meronymy).

Repetition is the restatement of the same lexical item. This is illustrated by the following:

Anna ate the apple. The apple was fresh.

Synonymy is used to refer to items of similar meaning just as, attractive and beautiful.

Antonymy is the relation between items of opposite meanings such as, hot and cold.

Hyponymy refers to items of 'general-specific' or 'an example of' relationship (Paltridge, 2012: 119). For example, vehicle is the co-hyponym of car.

Meronymy is a 'whole-part' relationship between items. For instance, cover and page are co-meronyms of the item book. In other words, book is the superordinate item of cover and page.

\subsubsection{Collocation}

Collocation is a combination of vocabulary items that co-occur together. It includes combinations of adjectives and nouns such as, 'fast food', verbs and nouns such as, 'run out of money', and other items such as, 'men' and 'women' (Platridge, 2012).

\section{The Data}

Under data, I shall present a critical analysis of the text and investigate the use of grammatical and lexical cohesive devices. Then, I shall provide some recommendations based on the correct and wrong usage of cohesive devices.

\subsection{Data Description and Framework}

The sample data is taken from The Michigan English Language Assessment Battery (MELAB), which is a standardized examination of English as a foreign language (EFL). MELAB assesses applicants' writing, reading, 
listening, and speaking skills. It is held for adult nonnative speakers of English, who are applying to universities in the United States, Canada, and the United Kingdom. Examinees undertake this test for the purpose of using English for academic purposes at universities and colleges.

The analyzed data is a sample of an examinee's essay writing who scored 73 in the test (see Appendix 1). The test taker had to choose one of two topics and complete the essay in 30 minutes. The prompt of the test taker was:

In some countries, the government policy is that all citizens should learn two foreign languages. Do you think this is a reasonable policy? Or do you think that other subjects should be a priority in school? Please use reasons and examples to support your opinion.

(MELAB Sample essays and commentary, 2013)

Following Halliday and Hasan's (1976) theory of cohesion, the text will be put to test by analysing the cohesive devices previously mentioned.

\subsection{Data Analysis}

\subsubsection{Grammatical Cohesive Devices}

\subsubsection{Reference}

The essay analysis shows that the test taker used a variety of references. Table 1 displays the number of each type of reference, and the total number of references used altogether (see Appendix 2).

\section{1- Personal, comparative and demonstrative references}

The student uses many instances of personal anaphoric references to refer to presupposed items in the text. For example, their (line 4) refers to businessman and partner (line 3), they (lines 6, 7, and 8) refers to students (lines 6 and 7), and their and they (line 15) refer to some people (line 14). However, some people is considered a generic reference because the writer does not specify who these people are.

It is clear that the applicant shows excessive use of the comparative phrase more and more, which sometimes leads to incorrect usage or disjointed ideas. However, there are other areas where comparative references are used effectively such as, other (line 7), more (lines $11 \& 16$ ), and different (line 12).

In the student's writing, only two cases of demonstrative references are used throughout the text. In both cases, the writer uses these as an anaphoric reference to refer to the reasons or advantages of learning two foreign languages.

\section{2- The definite article the}

The article the is mostly used as an exophoric reference to refer to the outside world shared between the writer and the reader. This is evident in most paragraphs such as, the government and the citizens (line 1), the students (line 7), the boss (line 11), and the internet (line 14).

\subsubsection{Ellipsis and Substitution}

In the essay, there are two types of ellipsis, but there is no evidence of substitution. Nominal ellipsis appears in line 8:

...then they can talk to someone easier, and also [0:they] can learn more.

In the second part of the sentence, the pronoun [they] is omitted.

In addition, the writer leaves out the clause [we can find] (line 16) to avoid repetition:

...then we can find more resources for the information, and also [0:we can find] more detail.

\subsubsection{Conjunction}

Alike references, conjunctions are prominent in the student's essay. The writer uses three types of conjunctions: additive, adversative, and causal (see Appendix 3). However, there are no cases of temporal conjunctions. The most additive conjunctions used are 'and' and 'also'. Though, there is one example in which the writer uses a different additive, and that is or (line 18). Moreover, the adversative but (line 15) is used to show contrasting ideas. The applicant also uses causal conjunctions such as, because (line 7), then (line 11), and so (line 20) to link sentences together.

\subsubsection{Lexical Cohesive Devices}

Throughout the essay, the student uses variations of reiteration such as, repetition, synonymy, antonymy, and 
meronymy (see appendix 5). For example, the sentence 'I agree the government policy of all of the citizens should learn two foreign languages.' is repeated in lines 1 and 21 to reassure the reader of the writer's point of view. Additionally, there are several items that re-occur in the text more than once to emphasize the writer's ideas such as, learn (5 occurrences), learning (5), language (4), travel(3), students(3), and world (2). Another example of reiteration is synonymy such as, speak (line 7) and talk (line 8). Near synonyms like resources and information are also used in line 16. Antonyms such as, lose and find appear in lines 15 and 16 to express opposite ideas. In addition, a number of co-meronyms are used by the writer. For instance, government is the superordinate item of the co-meronym citizens (line 1), internet is the superordinate of information (line 4), and company is the superordinate of boss (line 11).

\subsubsection{Final Remarks and Recommendations}

The analysis reveals that $71.08 \%$ of the grammatical devices used in the essay is reference (see Appendix 4). This might indicate that the writer has little background of the appropriate method of using reference. The remaining percentage $(28.92 \%)$ of the total grammatical devices applied in the text is divided between conjunctions and ellipsis. However, there is no evidence of substitution.

In addition, the student demonstrates the use of the lexical device reiteration but never tends to use collocation. It can be noted that repetition is used very frequently (see Appendix 5). To some extent, repeating lexical items is acceptable, but repeating the same item in a single paragraph more than twice could affect the cohesion of the text. This is clear in paragraph three when the writer repeats the item the boss three times. It is suggested that the student repeats the same items due to the limited knowledge of vocabulary.

In order to improve the writing, the writer could use synonymy or substitution to avoid repetition. Using substitution adds variety and creates links between parts of the text. Also, the writer could refrain using the same reference several times and refer to it with synonyms or superordinations. Overall, the text is meaningful to the reader and shows evidence of cohesion, but it requires improvements semantically and syntactically.

\section{Conclusion}

Cohesion occurs in a text if it has texture. In other words, a text is cohesive when the stretches of language are hung together with ties (Hasan, 1968). According to Halliday and Hasan (1976), these ties could be grammatical or lexical. Therefore, if the text makes sense to the reader, then it is clear that the writer accomplished the use of cohesive devices.

The data analysis used in this study reveals the importance of using cohesive devices to produce effective writing. Although the essay demonstrates the use of these devices, it still needs adjustments to reach a higher level of cohesion.

\section{References}

Bloor, T., \& Bloor, M. (2013). The functional analysis of English: A Hallidayan approach (3rd ed.). London: Routledge.

Halliday, M. A. K., \& Hasan, R. (1976). Cohesion in English. London: Longman.

Hasan, R. (1968). Grammatical cohesion in spoken and written English: Part one. University College, London (Communication Research Center); Harlow : Longmans.

MELAB sample essays and commentary. (2013, June 12). In CaMLA. [ONLINE] Retrieved October 30, 2013, from

http://www.cambridgemichigan.org/about-us/news/melab/melab-sample-essays-and-commentary-now-avail able

\section{Appendix 1}

\section{Sample Data}

I agree the government policy of all of the citizens should learn two foreign languages. The world is getting more closer than before. It is very easy for us to travel to another country. Students can go to another country for study. Business man can find a parnet from other country to improve thir business. Also, there are more and more information can find on the internet. All of these are base on languages.

There are more and more students travel to another country for study. They travel to another country because they want learn other language. If the students can speak more languages, then they can talk to someone easier, 
and also can learn more. Also, they can make some friends easily. These are the advantages for learing more languages.

International business is getting common. There are more and more companines located in whole world. If the boss of the company can speak more than one language, then the boss can find some parnets from different countries, then the boss can have a successful business easily. Learning two languages is also good for the people who is working.

There are more and more information can find on the internet. Some people will translate the information into their language. But sometimes they will lose some important information. If we can know other language, then we can find more resources for the information, and also more detail. Learning more languages can also learn more knowledges.

Appendix 2

Table 1. Reference

\begin{tabular}{|c|c|c|c|c|c|c|}
\hline Type of reference & \multicolumn{5}{|c|}{ Number of reference use } & $\begin{array}{c}\text { Total use of } \\
\text { reference }\end{array}$ \\
\hline \multirow{8}{*}{ Personal reference } & \multirow{2}{*}{ Reference } & \multirow{2}{*}{ Reference line } & \multirow{2}{*}{$\begin{array}{c}\text { Number of } \\
\text { devices }\end{array}$} & \multicolumn{2}{|r|}{ Total } & \multirow{13}{*}{59} \\
\hline & & & & No & $\%$ & \\
\hline & I & $1 / 20$ & 2 & \multirow{6}{*}{16} & \multirow{6}{*}{$27.12 \%$} & \\
\hline & it & 1 & 1 & & & \\
\hline & us & $2 / 18$ & 2 & & & \\
\hline & their & $4 / 15$ & 2 & & & \\
\hline & they & $6 / 7 / 8 / 15$ & 5 & & & \\
\hline & we & $16 / 18 / 19$ & 4 & & & \\
\hline $\begin{array}{l}\text { Demonstrative } \\
\text { reference }\end{array}$ & these & $5 / 9$ & 2 & 2 & $3.39 \%$ & \\
\hline \multirow{3}{*}{$\begin{array}{l}\text { Comparative } \\
\text { reference }\end{array}$} & more & $\begin{array}{c}2 / 4 / 6 / 7 / 8 / 9 / 10 / 11 / \\
14 / 16 / 17 / 18 / 20\end{array}$ & 20 & \multirow{3}{*}{\multicolumn{2}{|c|}{$25 \mid 42.37 \%$}} & \\
\hline & other & $3 / 7 / 16 / 18$ & 4 & & & \\
\hline & different & 12 & 1 & & & \\
\hline Definite Article the & the & $1 / 4 / 7 / 9 / 11 / 12 / 13 / 14 / 16 / 19 / 20 / 21$ & 16 & & $27.12 \%$ & \\
\hline
\end{tabular}


Appendix 3

Table 2. Conjunction

\begin{tabular}{|c|c|c|c|c|c|c|}
\hline Type of conjunction & \multicolumn{5}{|c|}{ Number of conjunction use } & $\begin{array}{l}\text { Total use of } \\
\text { conjunction }\end{array}$ \\
\hline \multirow{5}{*}{ Additive conjunction } & \multirow{2}{*}{ Conjunction } & \multirow{2}{*}{ Conjunction line } & \multirow{2}{*}{$\begin{array}{c}\text { Number of } \\
\text { devices }\end{array}$} & \multicolumn{2}{|r|}{ Total } & \multirow{9}{*}{22} \\
\hline & & & & No. & $\%$ & \\
\hline & and & $4 / 6 / 8 / 10 / 14 / 16 / 19$ & 7 & \multirow{3}{*}{15} & \multirow{3}{*}{$68.18 \%$} & \\
\hline & also & $4 / 8 / 13 / 16 / 17 / 19$ & 7 & & & \\
\hline & or & 18 & 1 & & & \\
\hline $\begin{array}{l}\text { Adversative } \\
\text { conjunction }\end{array}$ & but & 15 & 1 & 1 & $4.55 \%$ & \\
\hline \multirow{3}{*}{ Causal conjunction } & then & $8 / 11 / 12 / 16$ & 4 & \multirow{3}{*}{6} & \multirow{3}{*}{$27.27 \%$} & \\
\hline & because & 7 & 1 & & & \\
\hline & so & 20 & 1 & & & \\
\hline
\end{tabular}

Appendix 4

Table 3. Grammatical cohesive devices

\begin{tabular}{|c|c|c|c|}
\hline \multirow{3}{*}{ Total } & Grammatical Cohesive Device & \multicolumn{2}{|c|}{ Total use } \\
\cline { 2 - 4 } & & No. & \% \\
\hline \multirow{3}{*}{83} & Reference & 59 & $\mathbf{7 1 . 0 8 \%}$ \\
\cline { 2 - 4 } & Conjunction & 22 & $\mathbf{2 6 . 5 1 \%} \%$ \\
\cline { 2 - 4 } & Ellipsis & 2 & $\mathbf{2 . 4 1 \%} \%$ \\
\cline { 2 - 4 } & Substitution & - & - \\
\hline
\end{tabular}

Appendix 5

Lexical Cohesion

The lexical devices (Repetition, Synonymy, Near Synonym, Antonymy, Meronymy)

are highlighted in the following text.

I agree the government policy of all of the citizens should learn two foreign languages. The world is getting more closer than before. It is very easy for us to travel to another country. Students can go to another country for study. Business man can find a parnet from other country to improve thir business. Also, there are more and more information can find on the internet. All of these are base on languages.

There are more and more students travel to another country for study. They travel to another country because they want learn other language. If the students can speak more languages, then they can talk to someone easier, and also can learn more. Also, they can make some friends easily. These are the advantages for learing more languages.

International business is getting common. There are more and more companines located in whole world. If the boss of the company can speak more than one language, then the boss can find some parnets from different countries, then the boss can have a successful business easily. Learning two languages is also good for the people who is working.

There are more and more information can find on the internet. Some people will translate the information into their language. But sometimes they will lose some important information. If we can know other language, then 
we can find more resources for the information, and also more detail. Learning more languages can also learn more knowledges.

Learning two or more languages is good for us. We can go to other country for study, boss of the company can try to improve the company becomes a international company, and also we can learn more on the internet. There are the advantges of learning more than one languages. So I agree the government policy of all of citizens should learn two foreign language

\section{Copyrights}

Copyright for this article is retained by the author(s), with first publication rights granted to the journal.

This is an open-access article distributed under the terms and conditions of the Creative Commons Attribution license (http://creativecommons.org/licenses/by/3.0/). 